\title{
Factors That Restrict or Support Retention among RN-to-BSN Nursing Students: A Replication Study
}

\author{
Brelinda Kern \\ McKendree University, Lebanon, USA \\ Email: bre.kern@gmail.com
}

Received 20 January 2014; revised 23 March 2014; accepted 6 April 2014

Copyright (C) 2014 by author and Scientific Research Publishing Inc.

This work is licensed under the Creative Commons Attribution International License (CC BY).

http://creativecommons.org/licenses/by/4.0/

(c) (i) Open Access

\begin{abstract}
RN-to-BSN nursing programs fulfill a needed link to the BSN degree for nurses who hold associate or diploma degrees. Although enrollment rates are currently on the rise for all nursing programs retention remains an issue. Improving retention in nursing education, particularly RN-to-BSN programs, will help meet the demands for increasing numbers of BSN-educated nurses. The purpose of this study was to describe factors that restricted or promoted retention among RN-to-BSN students and examine if there was a difference in the measure of these factors between a group of senior students and junior students. Jeffreys' (2004) nursing undergraduate retention and success (NURS) model, a conceptual framework, was used to guide the study. A non-experimental, descriptive, comparison design was used. This study was a replication of Jeffreys' (2007) study utilizing a different population of RN-to-BSN students. Analysis was completed by descriptive techniques, and comparisons were made using independent $t$-tests. No significance was found between junior status students and senior status students for five factors of retention. Although all of the factors were found to be supportive, environmental factors were the least supportive and support from family and friends was found to the most supportive. More studies are needed focused on the RN-to-BSN student population to validate the findings of this study related to factors that restrict and support retention among this population so strategies can be developed to address the issues.
\end{abstract}

\section{Keywords}

Nursing; RN-to-BSN; Retention

\section{Introduction}

A need exists for baccalaureate-prepared nurses in all aspects of the nursing profession. Aiken and colleagues [1] 
were the first to identify improved patient outcomes when BSN-educated registered nurses (RN) work at the bedside. In later research, after accounting for nurse staffing and education, Aiken, Clarke, Sloane, Lake, and Cheney [2] found more positive job satisfaction as well as lower risks of death and decreased incidences of failure to rescue in a study analyzing the effects of nurse practice environments.

A better educated nursing workforce is associated with lower patient mortality. Combining the best nurse staffing with the most educated nurses resulted in the best patient outcomes; a $60 \%$ higher surgical mortality rate was reported with poorly staffed units and less educated RNs [1]. Aiken et al. [2] recommended that hospitals improve nurse staffing and advance nurse education to improve patient outcomes. A baccalaureate education in nursing provides for a more in-depth and diverse workforce of RNs prepared for research and the utilization of and participation in evidence-based practice and quality improvement.

Historically, an individual may enter the nursing profession through multiple levels of education: associate degree (ADN) typically attained from community colleges, diploma from hospital-based programs, or generic baccalaureate (BSN) degree from colleges and universities. Individuals entering the profession from associate and diploma programs have the option to return to school to earn a BSN and advance in the profession. Fulcher and Mullin [3] reported the most affordable and efficient access to the nursing profession is through ADN programs, resulting in the nation's greatest number of RNs, including minority nurses and nurses practicing where they attained their degrees, benefiting those in rural America. Associate degree and diploma graduates need to continue their education and earn a baccalaureate degree before they are able to go on to earn advanced degrees [4]-[6]. The RN to bachelors in nursing (RN-to-BSN) program fulfills the need for post-licensure graduates of ADN, and diploma programs to build on previous nursing education and earn the BSN degree while being employed as a RN.

This population of students has different needs and issues from generic undergraduate or second-degree students. Most of the RN-to-BSN student population have families, work full-time with extended and non-traditional hours, and have returned to school to further their education. Retention for this population is an issue because when crises occur, school is the first, and many times the only possible responsibility to be dropped.

Studies are needed that focus on the RN-to-BSN population to determine the issues that restrict and support their ability to remain in the educational program as well as develop strategies to address those issues. Additionally, replication studies are needed to give strength and validity to previous research.

Prior research on retention by Jeffreys [7] was replicated at a small private college in the Midwest in an attempt to understand the factors that support or restrict retention in a sample of the RN-to-BSN students. Jeffreys [7] [8] has conducted extensive research in the area of retention and developed the Nursing Undergraduate Retention and Success (NURS) model and the Student Perception Appraisal-Revised (SPA-R) instrument to measure the factors that promote or restrict retention.

\section{The Instrument}

The SPA-R is a 27-item survey, which addresses five factors thought to be influential in the retention of students (see Table 1). The five factors are: environmental (10 items); institutional and integration (5 items); personal academic (5 items); college facilities (5 items); and friend support (2 items). Items are scored on a four-point scale of restriction/support (severely restricted, moderately restricted, moderately supported, greatly supported) with additional choices for "does not apply” and "neutral” (does not restrict/support).

\section{Jeffreys' Study}

Jeffreys' [7] multisite study was guided by the NURS model and utilized the SPA-R to understand the perceptions of students related to factors that supported and restricted retention. Factor analysis of the SPA-R revealed the five factors noted above. The characteristics for each factor are outlined in Table 1. Environmental factors were found by Jeffreys to be the most restrictive related to retention. Friend-support factors were the most supportive. Students perceived faculty advisement and helpfulness as the major moderately supportive variable.

\section{Replication Study}

For this replication, a non-experimental, descriptive, comparison design was used as was used by Jeffreys [7]. Unlike Jeffreys' [7] original research, this study was implemented in only one setting. Participants consisted of 
Table 1. Factor characteristics.

\begin{tabular}{ll}
\hline Factor & Characteristics \\
\hline Environmental & $\begin{array}{l}\text { Financial status, family financial support, family emotional support, family responsibilities, } \\
\text { childcare arrangements, family crisis, employment hours, employment responsibilities, } \\
\text { encouragement by outside friends, living arrangements, and transportation. }\end{array}$ \\
Institutional interaction and integration & $\begin{array}{l}\text { Nursing faculty advisement and helpfulness, memberships in professional organizations, } \\
\text { encouragement by friends in class, professional events, peer mentoring-tutoring, and enrichment } \\
\text { programs within the institutional setting, but outside of class. }\end{array}$ \\
Personal academic & $\begin{array}{l}\text { Personal study skills, study hours, class attendance, credit hours enrolled, and general academic } \\
\text { services such as computer lab hours/access, counseling, and library services. Academic factors } \\
\text { also include course grade, semester grade point average (GPA), and overall GPA. }\end{array}$ \\
College facilities & $\begin{array}{l}\text { Computer lab, the library, and the nursing skills laboratory. } \\
\text { Informal study groups, informal cohorts of students who rely on each other for help with } \\
\text { Friend support }\end{array}$ \\
\hline
\end{tabular}

full-time and part-time, junior and senior level RN-to-BSN students. The RN-to-BSN program is a hybrid program with 31 credit hours of required nursing courses taught in a face-to-face format; the remaining courses, which include all general education requirements and all nursing electives, are taught online. The university has campuses in two states with multiple off-campus sites in which classes are conducted. Faculty members travel to each site to teach the face-to-face nursing courses.

\section{Permission to Conduct Study}

The protection of the participants was maintained throughout the study. The University Institutional Review Boards from two institutions approved the study before implementation.

\section{Data Collection}

An email was sent to all 208 students enrolled in the RN-to-BSN program by the nursing program chairperson. The email included an invitation to participate in the study, an informed consent, and directions for completing the survey and demographic data tools via an electronic media survey program, eSurveysPro ${ }^{\circledR}$. A specific date for completing the instruments was set. Two reminder emails were sent to the students at one week and again two days before the due date. The researcher received the completed surveys anonymously via electronic format through eSurveysPro. Data were collected over one four-week period.

\section{Results}

The needed sample size was calculated as 128 particpants, equally divided into the two groups of juniors and seniors. Of the 208 invitations, 84 students (40.4\%) responded by entering the survey site; 77 surveys (38.0\%) were adequately completed and used for data analysis. The response rate of $38 \%$ was commensurate with response rates normally encountered for surveys; however, it was well below the needed sample size,limiting confidence in the findings. Post hoc analysis based on initial parameters of medium effect size calculated actual achieved power to be 0.58, which increases the risk of committing a Type II error or rejecting a research hypothesis even though it does not occur due to chance. Sample size was recalculated to determine the number needed to detect a large effect size and found to require at least 52 participants, 26 cases per group [8]. Statistical analyses proceeded on the data provided by the 77 participants.

\section{Descriptive Analysis}

The sample represented students at the junior $(n=35,45.5 \%)$ and senior $(n=42,54.5 \%)$ levels. It consisted exclusively of females ( $n=77,100 \%)$ between the ages of 20 to 59 years $(M=37.53, S D=10.83)$; the sample was predominantly White $(n=72,93.5 \%)$, with only five African-American/Black $(n=5,6.5 \%)$ respondents. The number of dependent children ranged between zero and five $(M=1.03, S D=1.20)$. Only two respondents $(2.6 \%)$ were not currently employed; 14 (18.2\%) were employed on a part-time basis; 57 (74.0\%) were employed full-time; and three (3.9\%) reported their employment status as other with further explanation indicating that 
one was off due to recent surgery and two held both full-time and part-time jobs; one respondent (1.3\%) did not provide an answer to this question. Participants worked between 0 and 80 hours per week $(M=38.00, S D=$ 11.30). The majority ( $n=66,85.7 \%$ ) had been continuously enrolled in the nursing program. The total number of credit hours in which participants were currently enrolled ranged between 3 and $22(M=8.68, S D=3.47)$. Additional demographic details are presented in Table 2.

\section{Reliability Testing}

The scales used to measure the research variables were evaluated for reliability as internal consistency by means of Cronbach's alpha. An acceptable alpha is 0.70 and above; the criterion to identify poorly functioning items was a corrected item-total correlation below 0.30. The entire 27-item scale achieved an overall alpha of 0.77 . The individual subscales performed less well, revealing poor correlation with other items on the scale, meaning that the instrument did not consistently measure the scale with small effect size, an acknowledged limitation on the confidence of the results (see Table 2).

\section{Responses to the Variable Measures}

Descriptive statistics were obtained for the five research variables and used to answer the research questions. All of the factors were found to be positive; thus, all factors were supportive of the students' ability to continue in the program.

Table 3 provides a summary of reliability values, presented in ascending order. Based on the scale whereby 0 indicated that the item either did not apply or did not restrict or support, -2 indicated that the item greatly restricted, -1 indicated moderate restriction, +1 indicated moderate support, and +2 indicated great support.

\section{Discussion}

Analyses of the data revealed that although the participants viewed all of the factors as somewhat supportive, the least supportive factors were environmental, followed by college facilities. Personal academic factors closely followed, differing in the order of placement from Jeffreys' [7] findings. Mirroring Jeffreys' [7] findings, friend support was the most supportive, with institutional interaction and integration factors a distant second. The rankings of the factors, other than the most and least supportive in the replicated study, were different in order from the rankings found by Jeffreys [7]. Jeffreys [7] ranked the other factors, from most to least supportive, as: friend support, institutional interaction and integration, and college facilities, followed by personal academic factors; environmental factors were the least supportive.

Table 2. Descriptive statistics for the scores of the research variables $(N=77)$.

\begin{tabular}{lcccc}
\hline Variable & $M$ & $S D$ & Range & \multicolumn{1}{c}{$n$} \\
\hline Environmental factors & 0.23 & 0.46 & -0.80 to 1.40 & -0.40 to 0.80 \\
College facilities factors & 0.25 & 0.27 & -1.20 to 2.00 & -0.40 to 1.20 \\
Personal academic factors & 0.29 & 0.72 & 0.32 & 0.00 to 2.00 \\
Institutional integration factors & 0.33 & 0.61 & 77 \\
Friend support factors & 1.23 & & 77 \\
\hline
\end{tabular}

Table 3. Reliability statistics for the scores of the research variables $(\mathrm{N}=77)$.

\begin{tabular}{lcccc}
\hline Variable & Alpha & Corrected correlation & $>0.30$ & Yes \\
Environmental factors & 0.61 & $0.03-0.49$ & 77 & Only \#26 \\
College facilities factors & 0.35 & $0.01-0.34$ & Yes & 76 \\
Personal academic factors & 0.69 & $0.32-0.59$ & $0.18-0.38$ & Only \#2 \\
Institutional integration factors & 0.39 & 0.38 & Yes \\
Friend support factors & 0.55 & 77 & 77 \\
\hline
\end{tabular}




\section{Similarities and Differences between the Two Studies}

Similarities of the two studies are limited to the NURS model as the conceptual framework and the SPA-R as the instrument. Jeffreys' [7] study utilized a large multisite sample of academically and ethnically diverse mostly ADN students. The current study utilized a small homogenous sample of RN-to-BSN students at one small private university in the Midwest. While both student types are classified as non-traditional, there are inherent differences. The ADN students may work, but most do not work full-time or have families to care for. The RNto-BSN students work full-time with varied hours and they have family responsibilities.

\section{Implications}

Studies focused on nursing student retention have been determined to be important. Although major limitations existed due the small sample size and limited reliability of the subscales, important lessons can be learned from this replication study.

The RN-to-BSN student population has been understudied. However, given the recommendations of the Institute of Medicine 2011 report, [9] the requirement by magnet hospitals that a certain percentage of nurses are BSN prepared, and the interest among state boards of nursing in "BSN in Ten" initiatives [10] [11] this population will be growing in the future. RN-to-BSN students have different needs and characteristics than other nursing students. It is important to understand the differences in this student population to be able to address their needs as learners. Additionally, examination of the individual factors from this study may help educators understand the issues and recommendations for RN-to-BSN students.

Environmental factors, which include financial strain, family crises, change of employment or position, changing work or family responsibilities, and personal and children's activities, prevent students from being able to concentrate on school responsibilities. Knowledge of these least supportive items provides opportunities for discussion with current and prospective students and opportunities to develop plans to mitigate these factors. Encouraging open communication between students and faculty is the first step in addressing environmental factors for individual students. Faculty education about financial assistance available in the local area would be another important step in addressing these issues for students.

College facilities factors include items related to the library, nursing skills lab, tutors, counseling, computer lab, and writing center. The findings of this study showed that students in the RN-to-BSN program do not use very many on-campus services, except the library and the writing center, because most do not attend class on campus and many live several hours away. Students access services on line, call for support, and only visit the brick and mortar site for assistance they cannot access remotely. Revising the survey to eliminate services that do not exist or are not utilized by RN-to-BSN students and including services the students are known to utilize may provide an improved perception of the supportiveness of college facilities factors in an RN-to-BSN program.

Personal academic factors were not perceived as supportive or restrictive. Improved flexibility in student class and work schedules, reduced work responsibilities, and clear expectations of the number of hours required for success may improve participants' perceptions of personal academic factors as supportive.

Institutional interaction and integration factors included items not provided for current study participants, such as peer mentor and tutoring and nursing student support services; participants may have been confused by these questions. However, the faculty formally advises students twice per year and the students are encouraged to attend nursing professional events, with the school paying for one specific event each year. Including a requirement for attending nursing professional events in specified courses such as Leadership, creating a venue for peer mentoring and tutoring, and providing support services specific to the needs of nursing students may increase supportiveness of these factors.

Friend support factors were found as the most supportive and included encouragement by friends outside of school and by friends within class. Students attend class at off-campus sites located in local hospitals where they work or community colleges near their homes. Many students work and take classes together, forming a strong bond of support.

\section{Recommendations}

Recommendations for future studies include determining factors that support and restrict retention through a qu- 
alitative study where perceptions of the students can be written verbatim and explored through dialogue and conversation. Additionally, a mixed-methods study utilizing a revised survey, deleting those items that are not applicable to the population such as the nursing lab, and adding a section for open comments from the students may provide more useful results. Having a larger sample from multiple RN-to-BSN programs would also improve the reliability and validity of the results.

\section{Conclusion}

Studies focused on nursing student retention have been shown to be important. This non-experimental, descriptive, comparison designed, replicated study examined the factors that restricted and promoted retention among RN-to-BSN students. A lack of significance was found between junior status students and senior status students for five factors of retention. Although limitations exist, the study was congruent with previous studies [4] [7] [9] [12]-[15] for factors that support and restrict retention among a group of RN-to-BSN students at one small institution in the Midwest. All of the factors were found to be supportive; however, environmental factors were the least supportive, and support from family and friends was found to be the most supportive.

\section{Acknowledgements}

The author was a participant in the 2013 NLN Scholarly Writing Retreat sponsored by the NLN Foundation for Nursing Education.

\section{References}

[1] Aiken, L.H., Clarke, S.P., Cheung, R.B., Sloane, D.M. and Silber, J.F. (2003) Educational Levels of Hospital Nurses and Surgical Patient Mortality. JAMA, 290, 1617-1623. http://dx.doi.org/10.1001/jama.290.12.1617

[2] Aiken, L.H., Clarke, S.P., Sloane, D.M., Lake, E.T. and Cheney, T. (2009) Effects of Hospital Care Environment on Patient Mortality and Nurse Outcomes. Journal of Nursing Administration, 39, S45-S51. http://dx.doi.org/10.1097/NNA.0b013e3181aeb4cf

[3] Fulcher, R. and Mullin, C.M. (2011) A Data-Driven Examination of the Impact of Associate and Bachelor's Degree Programs and the Nation's Nursing Workforce (Policy Brief 2011-02PBL). American Association of Community Colleges, Washington DC. http://www.aacc.nche.edu/Publications/Briefs/Documents/2011-02PBL_DataDrivenNurses.pdf

[4] Lillibridge, J. and Fox, S.D. (2005) RN to BSN Education: What Do RNs Think? Nurse Educator, 30, 12-16. http://dx.doi.org/10.1097/00006223-200501000-00005

[5] Megginson, L.A. (2008) RN-BSN Education: 21st Century Barriers and Incentives. Journal of Nursing Management, 16, 47-55.

[6] Newton, S.E. (2008) The Impact of Community College Transfer on Entry-Level Baccalaureate Nursing Student Retention. Nurse Educator, 33, 45-48. http://dx.doi.org/10.1097/01.NNE.0000299498.30743.5e

[7] Jeffreys, M.R. (2007) Nontraditional Students' Perceptions of Variables Influencing Retention: A Multisite Study. Nurse Educator, 32, 161-167. http://dx.doi.org/10.1097/01.NNE.0000281086.35464.ed

[8] Faul, F., Erdfelder, E., Buchner, A. and Lang, A.-G. (2009) Statistical Power Analyses Using G*Power 3.1: Tests for Correlation and Regression Analyses. Behavior Research Methods, 41, 1149-1160. http://dx.doi.org/10.3758/BRM.41.4.1149

[9] Jeffreys, M.R. (2004) Nursing Student Retention: Understanding the Process and Making a Difference. Springer, New York.

[10] Institute of Medicine (2011) The Future of Nursing: Leading Change, Advancing Health. The National Academies Press, Washington DC.

[11] American Nurses Association (2008) Nursing Education. http://nursingworld.org/MainMenuCategories/Policy-Advocacy/State/Legislative-Agenda-Reports/NursingEducation

[12] Delaney, C. and Piscopo, B. (2007) There Really Is a Difference: Nurses' Experiences with Transitioning from RNs to BSNs. Journal of Professional Nursing, 23, 167-173. http://dx.doi.org/10.1016/j.profnurs.2007.01.011

[13] Hegge, M. and Larson, V. (2008) Stressors and Coping Strategies of Students in Accelerated Baccalaureate Nursing Programs. Nurse Educator, 33, 26-30. http://dx.doi.org/10.1097/01.NNE.0000299492.92624.95

[14] Robertson, S., Canary, C.W., Orr, M., Herberg, P. and Rutledge, D.N. (2010) Factors Related to Progression and Grad- 
uation Rates for RN-to-Bachelor of Science in Nursing Programs: Searching for Realistic Benchmarks. Journal of Professional Nursing, 26, 99-107. http://dx.doi.org/10.1016/j.profnurs.2009.09.003

[15] Rudel, R.J. (2006) Nontraditional Nursing Students: The Social Influences on Retention. Teaching and Learning in Nursing, 1, 47-54. http://dx.doi.org/10.1016/j.teln.2006.06.002 